\title{
GREEN SUPPLY CHAIN MANAGEMENT E LOGÍSTICA REVERSA: UMA ANÁLISE SISTEMÁTICA DOS ARTIGOS
}

\author{
GREEN SUPPLY CHAIN MANAGEMENT AND REVERSE LOGISTICS: A SYSTEMATIC \\ ANALYSIS OF ARTICLES
}

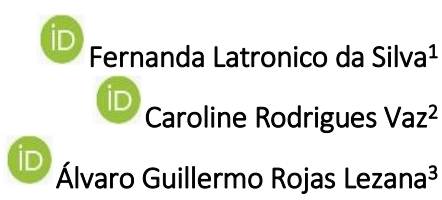

${ }^{1}$ Doutora em Engenharia de Produção Universidade Federal de Santa Catarina fernanda.latronico@posgrad.ufsc.br

${ }^{2}$ Doutora em Engenharia de Produção Professora da Universidade Federal de Santa

Catarina

caroline.vaz@ufsc.br

${ }^{3}$ Doutor em Ingeniería Industrial Professor da Universidade Federal de Santa Catarina alvaro.lezana@ufsc.br
Resumo: O Green supply chain management baseia-se no reconhecimento de que os efeitos ambientais de uma organização incluem os impactos ambientais de produtos e processos desde a extração das matérias-primas, percorrendo os produtos produzidos, até a disposição final destes bens, incluindo a logística reversa. Este estudo tem como objetivo analisar os artigos mais relevantes inerentes aos temas GSCM e logística reversa, identificando lacunas em relação a essas duas abordagens por meio da análise sistemática dos artigos. Após a análise bibliométrica, foi realizada a análise sistemática que averiguou os tipos de artigos, a unidade de análise dos artigos e as oportunidades de pesquisas. Observou-se que as principais lacunas de pesquisa dizem respeito à eficiência dos processos para diminuir os custos, criar estratégias ambientais a fim de melhorar a imagem da organização, desenvolver medidas de avaliação de desempenho, além de considerar a avaliação do ciclo de vida e questões de sustentabilidade.

Palavras-Chave: Green supply chain management. Logística reversa. Análise sistemática.

Abstract: Green supply chain management is based on the recognition that the environmental effects of an organization include the environmental impacts of products and processes from the extraction of raw materials, through the products produced, to the final disposal of these goods, including reverse logistic. This study aims to analyze the most relevant articles inherent to the themes GSCM and reverse logistics, identifying gaps in relation to these two approaches through the systematic analysis of the articles. After the bibliometric analysis, a systematic analysis was performed to ascertain the types of articles, the article analysis unit and the research opportunities. It was noted that the major research gaps concern the efficiency of processes to reduce costs, create environmental strategies to improve the organization's image, develop performance measurement measures, and consider life cycle assessment and issues of sustainability.

Keywords: Green supply chain management. Reverse logistics. Systematic Analysis. 


\section{Introdução}

A nova era ambiental representa um novo desafio na fabricação e na produção de novos produtos. O desafio se concentra principalmente em mudanças construtivas nos sistemas produtivos para que a proteção ambiental e o desenvolvimento industrial possam caminhar juntos (Beamon, 1999).

Dois assuntos que ganham destaque atualmente são os conceitos de Green Supply Chain Management (GSCM) e a logística reversa (LR). O GSCM, também conhecido por Gestão da Cadeia de Suprimento Verde, baseia-se no reconhecimento de que os efeitos ambientais de uma organização incluem os impactos ambientais de produtos e processos, desde a extração das matérias-primas, percorrendo os produtos produzidos, até a disposição final destes bens (Lamming \& Hampson, 1996).

Dessa forma, o GSCM é a gestão de materiais e recursos naturais desde o projeto do produto, passando pelo fornecimento e distribuição, até o seu consumo final, incluindo a logística reversa. A logística reversa aborda a atual preocupação com a disposição final dos produtos, considerando os aspectos legais e ambientais. É um tema de interesse crescente entre os pesquisadores e empresas, que buscam novas formas de reduzir os impactos ambientais gerados pelo processo produtivo ao longo da cadeia de suprimentos.

A integração do pensamento ambiental na gestão da cadeia de suprimentos inclui design de produtos, seleção de materiais, terceirização, fabricação, processos, entrega de produtos ao consumidor e o gerenciamento dos produtos após a sua vida útil (Srivastava, 2007). Assim, a estrutura tradicional da cadeia de suprimento verde deve ser estendida até os mecanismos de recuperação dos produtos após sua vida útil (Beamon, 1999).

Ao longo da década de 2000, o Green Supply Chain Management (GSCM) eclodiu como um importante componente estratégico das empresas e de suas cadeias de suprimentos (Lee, 2008). Estrategicamente, as empresas identificaram oportunidades de melhorar as suas operações logísticas nas últimas décadas (Zhang \& Lu, 2005).

Os estudos de GSCM e logística reversa se concentram especialmente em avaliar as perspectivas táticas e operacionais das empresas, tais como, planejamento de produção, gestão de estoques, gestão de transportes, design dos produtos e sistema de informação (Cheng \& Lee, 2010). São oportunidades de melhorar o retorno dos resíduos ou reduzir o desperdício a partir da gestão eficiente (Handfield, Sroufe, \& Walton, 2005).

Conforme Genchev (2009) a preocupação com as questões ambientais e o movimento do retorno de bens e serviços na cadeia de suprimentos está se tornando uma atividade necessária e essencial de gestão, independente do setor de produtos ou serviços envolvidos. Assim, as empresas começam a reconhecer que atingir o cliente final não representa o fim da jornada para o produto.

Nesse contexto, o artigo tem como objetivo analisar os artigos mais relevantes inerentes aos temas Green Supply Chain Management (GSCM) e logística reversa, identificando lacunas em relação a essas duas abordagens por meio da análise sistemática dos artigos. 
Após essa introdução, o trabalho se encontra estruturado da seguinte forma: na seção 2, encontram-se os procedimentos metodológicos, na seção 3, é exposta a análise bibliométrica e análise sistemática dos artigos, e na seção 4, é apresentada a conclusão.

\section{Procedimentos metodológicos}

Os procedimentos metodológicos envolvem as seguintes etapas: i) definição das palavraschave; ii) filtragem do banco dos artigos; iii) seleção dos artigos e análise bilbiométrica; e iv) análise sistemática. A Figura 1 apresenta as etapas de pesquisa.

Figura 1 - Etapas da pesquisa

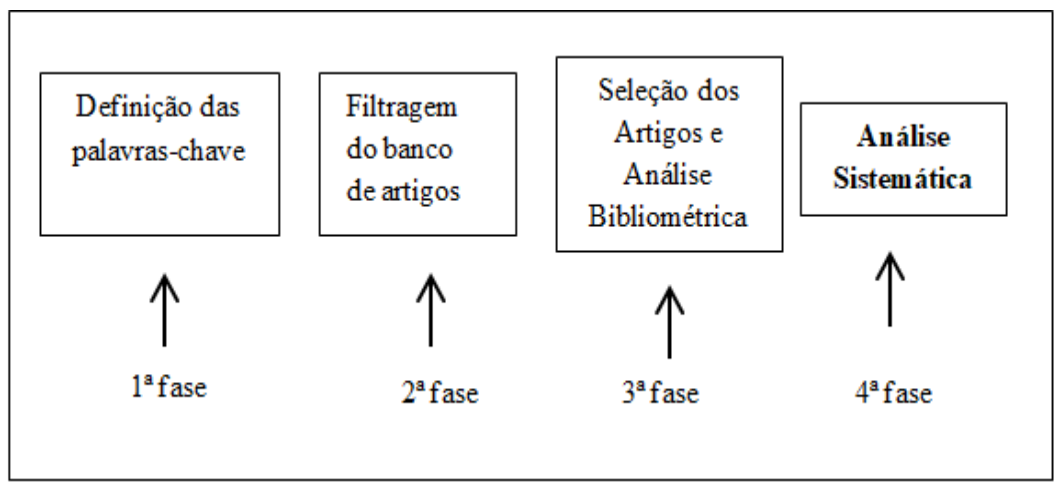

Fonte: Elaborado pelos autores.

\subsection{Definições das palavras-chave e das bases de dados}

A definição das palavras-chave desta pesquisa envolveu dois temas: green supply chain management e reverse logistics. O Quadro 1 define as palavras-chave utilizadas.

Quadro 1 - Palavras-chave da pesquisa

Reverse Logistics
"Reverse Logistics" $\quad$ and "Green supply chain management"
"Reverse supply chain "
"Close loop supply chain"

Fonte: Elaborado pelos autores.

Para a composição do portfólio bibliográfico, foram definidas as bases de dados Science Direct, ISI Web of Science, Scopus e Wiley Online Library. Nesse caso, foram feitas três pesquisas em cada base de dados. 
A pesquisa foi realizada por meio da busca de artigos publicados em periódicos, sem limitação de período para poder verificar a evolução dos dois temas ao longo dos anos. A quantidade total de artigos encontrados nas referidas bases de dados foi resultado de palavras-chave pesquisadas nos títulos, nos resumos e nas palavras-chaves dos artigos. O conjunto de 3589 artigos encontrados passou a compor o banco de artigos brutos, conforme Tabela 1.

Tabela 1: Quantidade de artigos científicos encontrados nas bases de dados

\begin{tabular}{c|c}
\hline Base de dados & Quantidade de artigos \\
Scopus & 1837 \\
Web of Science & 571 \\
Science Direct & 734 \\
Wiley Online Library & 450 \\
\hline
\end{tabular}

Fonte: Elaborado pelos autores.

Os periódicos encontrados em cada uma das bases de dados foram transferidos para o software EndNote $X 5^{\circ}$, com a finalidade de ajudar na manipulação e no registro das informações que servem de base para a construção do referencial teórico.

\subsection{Filtragens do banco de artigos brutos}

A filtragem foi realizada em três etapas: i) em relação à redundância; ii) quanto ao alinhamento do título; iii) no que diz respeito à relevância científica.

A primeira etapa do processo de filtragem do banco de artigos brutos foi relacionada à redundância. Primeiramente, selecionaram-se os 3589 artigos das bases Scopus, ISI Web of Science, Science Direct e Wiley Online Library que haviam sido exportados para o software EndNote X $5^{\circ}$.

A segunda etapa da filtragem compreende a leitura dos títulos dos artigos, de modo a descartar parte dos artigos que estão no banco de artigos brutos. Esse processo resultou na eliminação de 1102 artigos. A amostra não repetida foi composta por 2487 artigos a serem verificados, obtendo-se posteriormente 311 artigos para compor o banco de artigos brutos com o título alinhado ao foco da pesquisa.

Após a leitura dos resumos dos 311 artigos, 45 estavam alinhados com o tema e se destacaram para o presente estudo. A terceira etapa da filtragem do banco de artigos averiguou a relevância científica dos artigos selecionados como critério de permanência dos mesmos no banco de artigos da pesquisa.

\section{Resultados}


A análise dos resultados está segregada em duas subseções: i) análise bibliométrica, que compreende o estudo das referências dos artigos do portfólio e a classificação destes conforme referência acadêmica na amostra; e ii) análise sistemática.

\subsection{Análise Bibliométrica}

A Figura 2 mostra os anos de publicações. Verifica-se que no ano de 2002 teve maior numero de publicações do tema LR. Entre os anos de 2004 a 2009 se concentram o maior número de pesquisas referentes aos dois temas.

Figura 2 - Quantidade de publicações dos temas LR e GSCM

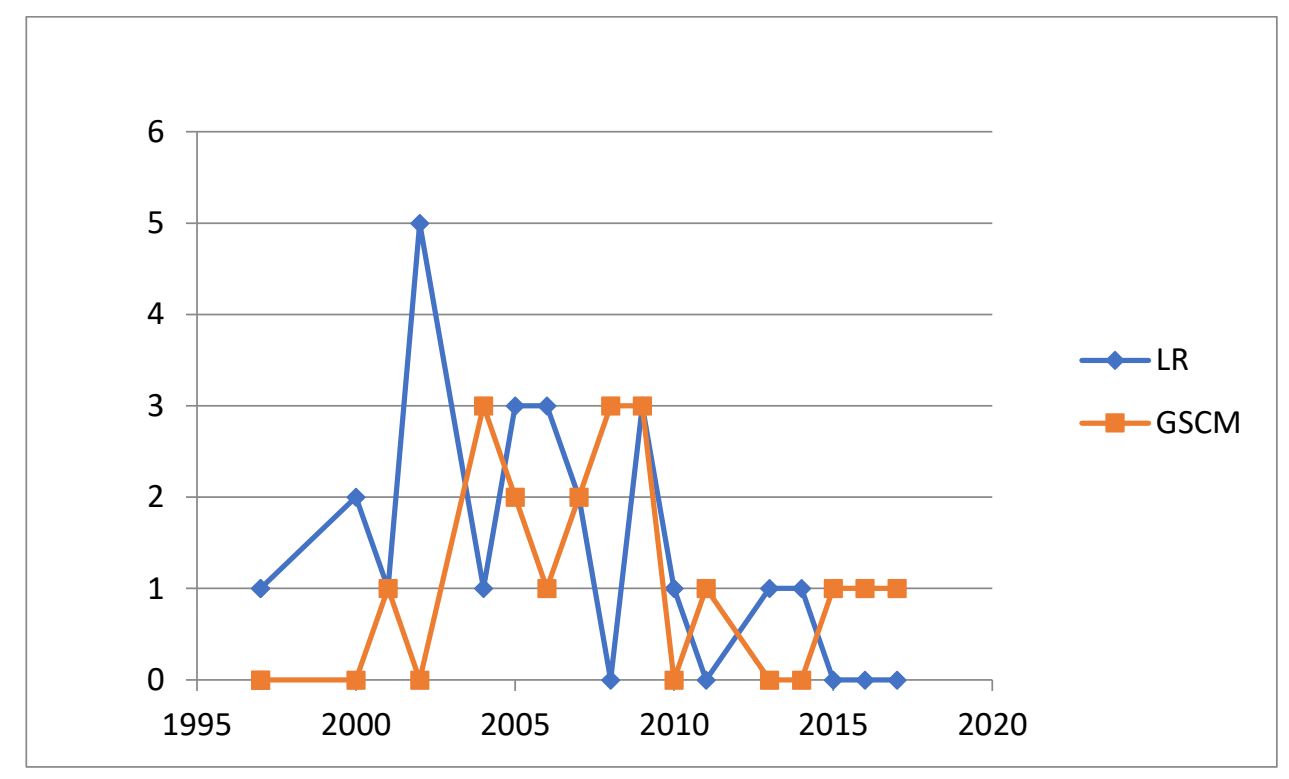

Fonte: Elaborado pelos autores.

Nos últimos anos predominaram as pesquisas voltadas ao GSCM. É um tema abrangente, que envolve a sustentabilidade em toda a cadeia de suprimentos, incluindo a LR. O tema GSCM cresceu principalemente a partir de 2000.

A Figura 3 apresenta os números de citações dos artigos mais relevantes. Considereou-se somente os artigos que tiveram número de citações superiores a 100 dentro do portfólio.

Figura 3 - Número de citações por artigos 


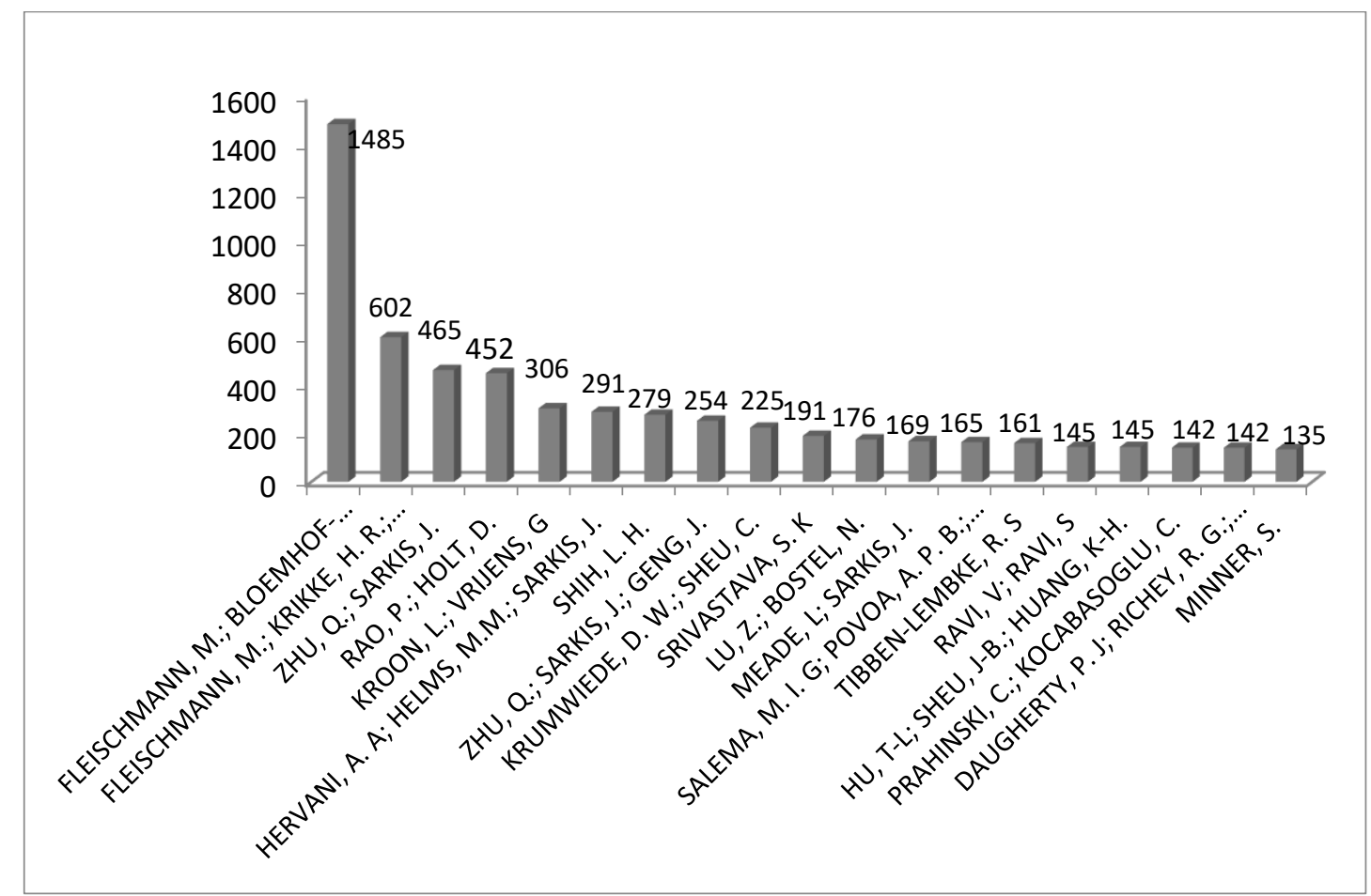

Fonte: Elaborado pelos autores.

Observa-se que o artigo mais citado foi o intitulado "Quantitative models for reverse logistics: A review" de Fleischmann, Dekker,Van der Lann and Wassenhove (1997) com 1485 citações. Na sequência, encontra-se o artigo intitulado "A characterisation of logistics networks for product recovery" também de Fleischmann, Krikke, Dekker and Flapper (2000) com 602 citações.

Em relação à relevância dos autores, verifica-se que o autor Joseph Sarkis possui 7 artigos no portfólio bibliográfico, afirmando-o como um dos principais pesquisadores nas áreas de operações e gestão ambiental.

O grau de relevância dos periódicos foi obtido por meio da análise da quantidade de artigos que cada periódico possui no portfólio bibliográfico, conforme apresentando pela Figura 4.

Figura 4 - Número de artigos por periódicos 


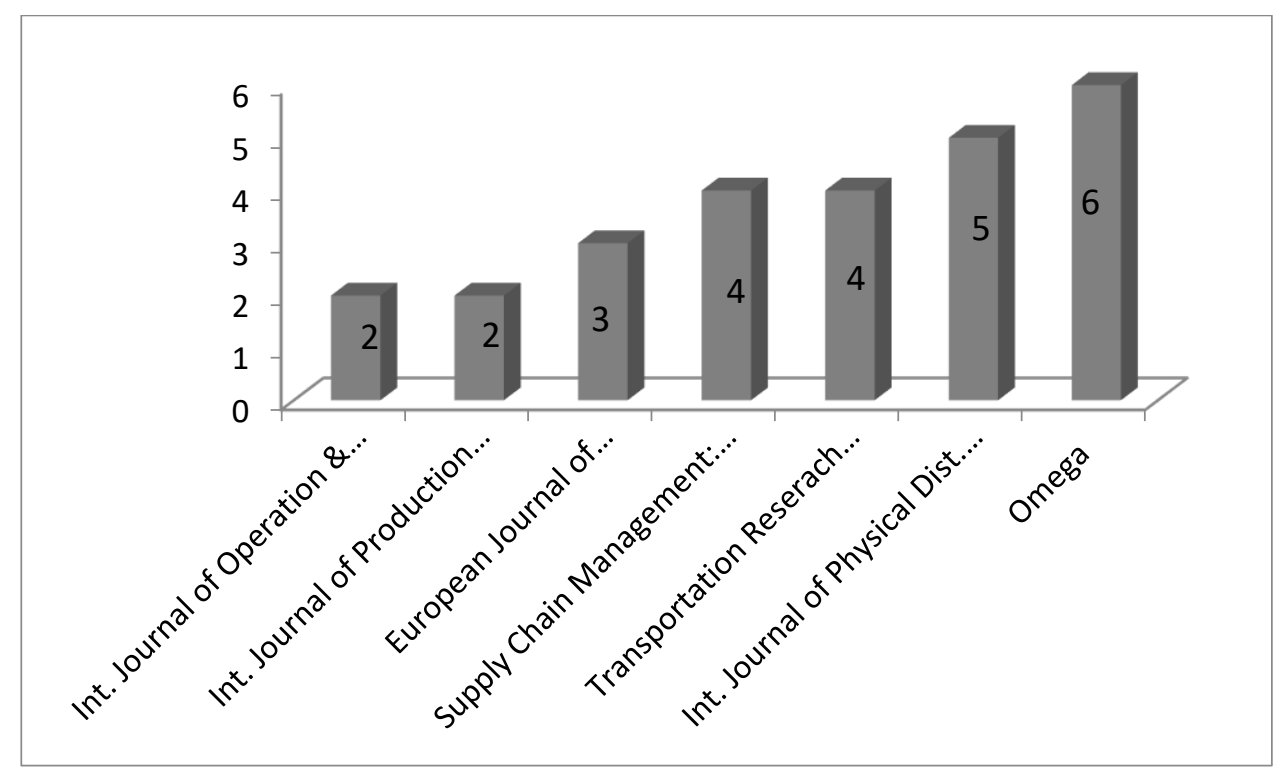

Fonte: Elaborado pelos autores.

Dos 45 artigos, 6 artigos foram publicados na revista Omega e 5 no International Journal of Physical Distribuition\& Logistics. Observa-se também que o tema dessa pesquisa é de interesse em diferentes periódicos internacionais.

Quanto às palavras-chaves mais utilizadas, a Figura 5 apresenta as palavras-chaves que aparecem nos artigos mais de uma vez. Do total de 164 palavras-chave, 8 foram encontradas mais de uma vez nos artigos.

Figura 5 - Relação das palavras-chave mais utilizadas

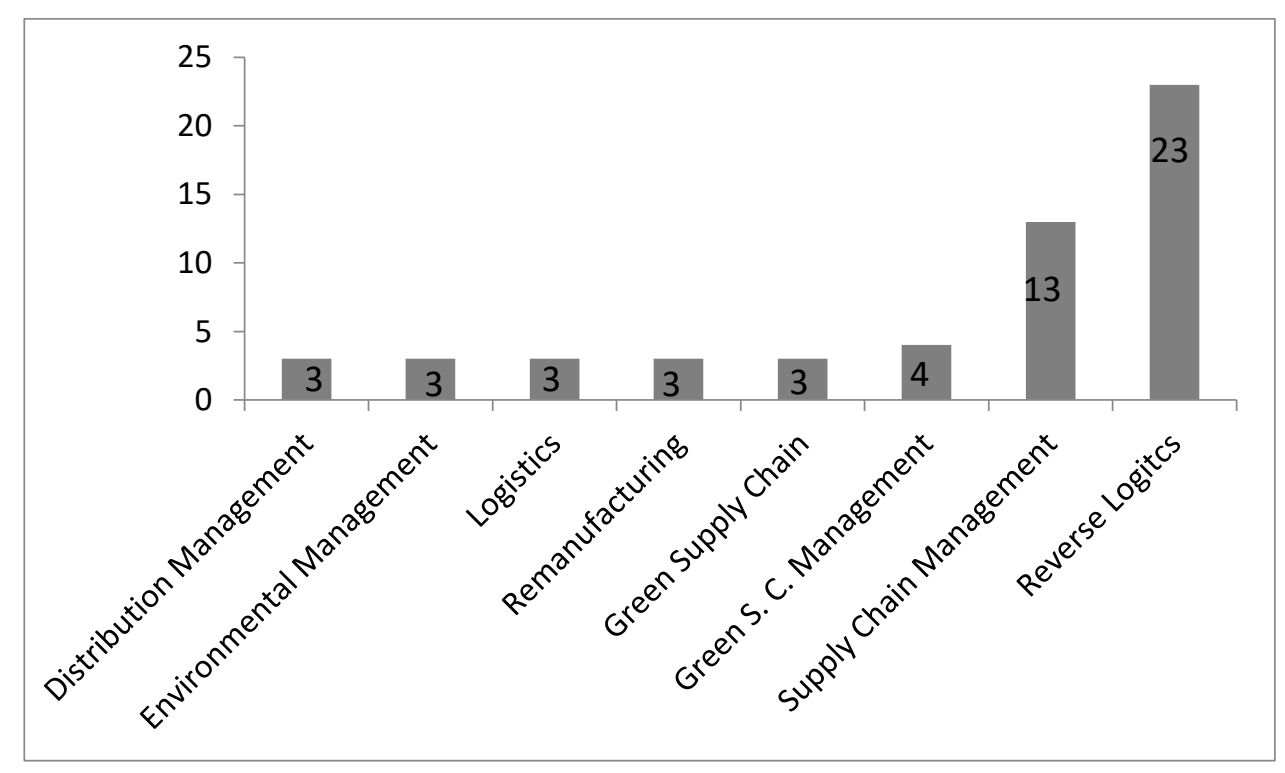

Fonte: Elaborado pelos autores.

Observa-se a palavra-chave que mais se destaca é "reverse logistics", presente em 23 artigos. A segunda palavra-chave mais empregada foi "supply chain management", utilizada em 13 artigos. A 
Silva, F. L. da, Vaz, C. R., \& Lezana, A. G. R. (2020, out./dez.). Green supply chain management e logística reversa: uma análise sistemática dos

palavra-chave "green supply chain management"encontra-se em quatro artigos, mostrando que a abrangência da palavra-chave supply chain management é superior ao green supply chain management.

\subsection{Análise Sistemática}

Conforme o Quadro 2, a análise realizada foi organizada e sistematizada conforme os seguintes critérios: i) tipo de artigo; ii) objetivo do artigo; iii) unidade de análise; e iv) principais resultados.

Quadro 2 - Análise sistemática dos artigos

\begin{tabular}{|c|c|c|c|c|}
\hline Artigos & $\begin{array}{ll}\text { Tipo } & \text { de } \\
\text { Artigo } & \end{array}$ & Objetivos & $\begin{array}{l}\text { Unidade de } \\
\text { análise }\end{array}$ & Principais resultados \\
\hline $\begin{array}{l}\text { Quantitative models for } \\
\text { reverse logistics: A } \\
\text { review }\end{array}$ & Empírico & $\begin{array}{l}\text { Discutir as implicações } \\
\text { e esforços na área de } \\
\text { planejamento, } \\
\text { distribuição e controle } \\
\text { referentes aos } \\
\text { processos de } \\
\text { reutilização. }\end{array}$ & $\begin{array}{l}\text { Gestão de } \\
\text { Retornos. }\end{array}$ & $\begin{array}{l}\text { Novos fluxos de materiais reversos } \\
\text { com os fluxos tradicionais aumentam } \\
\text { a complexidade dos sistemas } \\
\text { envolvidos. }\end{array}$ \\
\hline $\begin{array}{l}\text { A characterisation of } \\
\text { logistics networks for } \\
\text { product recovery }\end{array}$ & Teórico & $\begin{array}{l}\text { Revisar os estudos de } \\
\text { casos recentes sobre } \\
\text { projeto da rede de } \\
\text { logística para a } \\
\text { recuperação de } \\
\text { produtos. }\end{array}$ & $\begin{array}{l}\text { Redes de } \\
\text { recuperação } \\
\text { de produtos. }\end{array}$ & $\begin{array}{l}\text { Diferentes projetos de } \\
\text { desmontagem, recuperação e } \\
\text { eliminação, devem ser instalados na } \\
\text { rede de logística reversa. }\end{array}$ \\
\hline $\begin{array}{l}\text { Relationships between } \\
\text { operational practices } \\
\text { and performance } \\
\text { among early adopters } \\
\text { of green supply chain } \\
\text { management }\end{array}$ & Empírico & $\begin{array}{l}\text { Investigar como gestão } \\
\text { da qualidade total e o } \\
\text { just-in-time podem } \\
\text { influenciar nas práticas } \\
\text { de desempenho do } \\
\text { GSCM. }\end{array}$ & $\begin{array}{l}\text { Avaliação de } \\
\text { Desempenho } \\
\text { Ambiental. }\end{array}$ & $\begin{array}{l}\text { Técnicas de gestão de operações, } \\
\text { incluindo gestão da qualidade total } \\
\text { podem ajudar a melhorar os fatores } \\
\text { de desempenho operacionais, tais } \\
\text { como a eficiência, serviço e } \\
\text { qualidade. }\end{array}$ \\
\hline $\begin{array}{l}\text { Do green supply chains } \\
\text { lead to competitiveness } \\
\text { and economic } \\
\text { performance? }\end{array}$ & Teórico & $\begin{array}{l}\text { Identificar possíveis } \\
\text { ligações entre o GSCM } \\
\text { com o desempenho } \\
\text { econômico e a } \\
\text { competitividade } \\
\text { empresarial. }\end{array}$ & $\begin{array}{l}\text { Avaliação de } \\
\text { Desempenho } \\
\text { Ambiental. }\end{array}$ & $\begin{array}{l}\text { A análise identificou que o greening } \\
\text { eficiente leva a uma integração da } \\
\text { cadeia de suprimento que acaba por } \\
\text { conduzir a uma maior } \\
\text { competitividade e desempenho } \\
\text { econômico. }\end{array}$ \\
\hline $\begin{array}{l}\text { Returnable containers: } \\
\text { an example of reverse } \\
\text { logistics }\end{array}$ & Empírico & $\begin{array}{l}\text { Descrever um modelo } \\
\text { quantitativo para ser } \\
\text { utilizado no processo } \\
\text { de planejamento de } \\
\text { retorno de recipientes. }\end{array}$ & $\begin{array}{l}\text { Gestão de } \\
\text { Retornos }\end{array}$ & $\begin{array}{l}\text { Embora o uso de embalagem } \\
\text { retornável seja ecologicamente } \\
\text { correto, as empresas irão considerar } \\
\text { as implicações econômicas e de } \\
\text { logística em primeiro lugar. }\end{array}$ \\
\hline $\begin{array}{l}\text { Performance } \\
\text { measurement for green } \\
\text { supply chain } \\
\text { management }\end{array}$ & Teórico & $\begin{array}{l}\text { Apresentar e fornecer } \\
\text { uma visão geral das } \\
\text { questões relacionadas } \\
\text { com a avaliação de } \\
\text { desempenho ambiental } \\
\text { no GSCM. }\end{array}$ & $\begin{array}{l}\text { Avaliação de } \\
\text { Desempenho } \\
\text { Ambiental. }\end{array}$ & $\begin{array}{l}\text { As partes interessadas fizeram com } \\
\text { que as organizações considerassem } \\
\text { explicitamente o seu planejamento } \\
\text { estratégico, de execução e } \\
\text { operacional voltadas ao desempenho } \\
\text { ambiental. }\end{array}$ \\
\hline $\begin{array}{l}\text { Reverse logistics system } \\
\text { planning for recycling } \\
\text { electrical appliances } \\
\text { and computers in } \\
\text { Taiwan }\end{array}$ & Empírico & $\begin{array}{l}\text { Propor um modelo que } \\
\text { minimize o custo total } \\
\text { e o custo fixo, custos } \\
\text { de eliminação final e o } \\
\text { custo de aterros. }\end{array}$ & Custos na LR & $\begin{array}{l}\text { O modelo confirma o benefício do } \\
\text { compartilhamento de instalações de } \\
\text { reciclagem. }\end{array}$ \\
\hline
\end{tabular}




\begin{tabular}{|c|c|c|c|c|}
\hline $\begin{array}{l}\text { Green supply chain } \\
\text { management in China: } \\
\text { pressures, practices and } \\
\text { performance }\end{array}$ & Empírico & $\begin{array}{l}\text { Avaliar e descrever os } \\
\text { drivers do GSCM, } \\
\text { práticas e desempenho } \\
\text { entre organizações de } \\
\text { fabricação chinesa. }\end{array}$ & $\begin{array}{l}\text { Avaliação de } \\
\text { Desempenho } \\
\text { Ambiental. }\end{array}$ & $\begin{array}{l}\text { Empresas chinesas destacam suas } \\
\text { filosofias exportadoras buscando as } \\
\text { normas internacionais, como ISO } \\
9000 \text { e ISO14000. No entanto, GSCM } \\
\text { ainda está na fase de precoce na } \\
\text { China. }\end{array}$ \\
\hline $\begin{array}{l}\text { A model for reverse } \\
\text { logistics entry by third- } \\
\text { party providers }\end{array}$ & Empírico & $\begin{array}{l}\text { Ajudar as empresas a } \\
\text { atingir um novo } \\
\text { mercado com a LR por } \\
\text { meio de uma revisão } \\
\text { das práticas atuais em } \\
\text { empresas terceirizadas. }\end{array}$ & $\begin{array}{l}\text { LR em } \\
\text { empresas } \\
\text { terceirizadas }\end{array}$ & $\begin{array}{l}\text { O modelo ajudou as empresas } \\
\text { terceirizadas na tomada de decisão. } \\
\text { O modelo fornecido é estruturado } \\
\text { para a decisão e fornece orientação } \\
\text { necessária para tal decisão. }\end{array}$ \\
\hline $\begin{array}{l}\text { Network design for } \\
\text { reverse logistics }\end{array}$ & Empírico & $\begin{array}{l}\text { Desenvolver um } \\
\text { modelo para a } \\
\text { localização-alocação de } \\
\text { instalações para uma } \\
\text { rede de baixo custo e } \\
\text { LR eficiente. }\end{array}$ & Custos na LR & $\begin{array}{l}\text { Experimentação com variações de } \\
\text { tempos de processamento, custos de } \\
\text { processamento e taxas de } \\
\text { recuperação fornece insights para } \\
\text { várias decisões. }\end{array}$ \\
\hline $\begin{array}{l}\text { A facility location model } \\
\text { for logistics systems } \\
\text { including reverse flows: } \\
\text { The case of } \\
\text { remanufacturing } \\
\text { activities }\end{array}$ & Empírico & $\begin{array}{l}\text { Apresentar um modelo } \\
\text { de localização de } \\
\text { instalações de LR que } \\
\text { cobrem as atividades } \\
\text { de remanufatura em } \\
\text { fluxos direto e reverso. }\end{array}$ & $\begin{array}{l}\text { Rede de } \\
\text { recuperação } \\
\text { de produtos }\end{array}$ & $\begin{array}{l}\text { Os fluxos reversos influenciam as } \\
\text { decisões sobre a localização e } \\
\text { alocação. Essa influência varia de } \\
\text { acordo com a magnitude dos fluxos } \\
\text { reversos, a sua distribuição e sua } \\
\text { correlação com os fluxos de retornos. }\end{array}$ \\
\hline $\begin{array}{l}\text { A conceptual model for } \\
\text { selecting and evaluating } \\
\text { third-party reverse } \\
\text { logistics providers }\end{array}$ & Empírico & $\begin{array}{l}\text { Oferecer suporte para } \\
\text { o uso e o envolvimento } \\
\text { de provedores } \\
\text { terceirizados de } \\
\text { logística dentro do } \\
\text { quadro de LR. }\end{array}$ & $\begin{array}{l}\text { LR em } \\
\text { empresas } \\
\text { terceirizadas. }\end{array}$ & $\begin{array}{l}\text { Este trabalho abordou a necessidade } \\
\text { de um modelo de tomada de decisão } \\
\text { e estratégias para auxiliar a gestão da } \\
\text { empresa terceirizada responsável } \\
\text { pela LR. }\end{array}$ \\
\hline $\begin{array}{l}\text { An optimization model } \\
\text { for the design of a } \\
\text { capacitated multi- } \\
\text { product reverse } \\
\text { logistics network with } \\
\text { uncertainty }\end{array}$ & Empírico & $\begin{array}{l}\text { Apresentar um novo } \\
\text { modelo generalizado } \\
\text { para o projeto de redes } \\
\text { de logística reversa. O } \\
\text { modelo baseia-se na } \\
\text { rede de recuperação. }\end{array}$ & $\begin{array}{l}\text { Rede de } \\
\text { recuperação } \\
\text { do produto. }\end{array}$ & $\begin{array}{l}\text { Este trabalho desenvolve um modelo } \\
\text { de rede capacitada de multi-produto } \\
\text { de LR para a incerteza e permite } \\
\text { qualquer número de produto e } \\
\text { garante capacidade total para cada } \\
\text { unidade a um custo mínimo. }\end{array}$ \\
\hline $\begin{array}{l}\text { Life after death: reverse } \\
\text { logistics and the } \\
\text { product life cycle }\end{array}$ & Teórico & $\begin{array}{l}\text { Estudar a forma como } \\
\text { a LR é afetada por } \\
\text { mudanças nas vendas } \\
\text { ao longo do ciclo de } \\
\text { vida do produto. }\end{array}$ & $\begin{array}{l}\text { Ciclo de vida } \\
(\mathrm{ACV})\end{array}$ & $\begin{array}{l}\text { É importante saber em que estágio } \\
\text { de vida de produtos de uma empresa } \\
\text { ele ocupa a fim de se preparar para } \\
\text { os desafios e oportunidades futuras. }\end{array}$ \\
\hline $\begin{array}{l}\text { Analysis of interactions } \\
\text { among the barriers of } \\
\text { reverse logistics }\end{array}$ & Empírico & $\begin{array}{l}\text { O objetivo é analisar a } \\
\text { interação entre as } \\
\text { principais barreiras que } \\
\text { dificultam ou impedem } \\
\text { a aplicação da LR nas } \\
\text { indústrias } \\
\text { automobilística } \\
\text { indiana. }\end{array}$ & $\begin{array}{l}\text { LR na indústria } \\
\text { automobilístic } \\
\text { a. }\end{array}$ & $\begin{array}{l}\text { Utilizando a metodologia de ISM, foi } \\
\text { desenvolvido um modelo de } \\
\text { relacionamento entre as barreiras da } \\
\text { logística reversa nas indústrias de } \\
\text { automóveis indiana. A falta de } \\
\text { consciência das práticas de LR é uma } \\
\text { barreira muito significativa. }\end{array}$ \\
\hline $\begin{array}{l}\text { A reverse logistics cost } \\
\text { minimization model for } \\
\text { the treatment of } \\
\text { hazardous wastes }\end{array}$ & Empírico & $\begin{array}{l}\text { Apresentar um modelo } \\
\text { de LR de resíduos } \\
\text { perigosos incluindo a } \\
\text { recolha, } \\
\text { armazenamento, } \\
\text { processamento e } \\
\text { distribuição. }\end{array}$ & $\begin{array}{l}\text { LR de resíduos } \\
\text { perigosos. }\end{array}$ & $\begin{array}{l}\text { Ao identificar as atividades críticas e } \\
\text { os requisitos básicos envolvidos no } \\
\text { processo de operações de LR de } \\
\text { resíduos perigosos, a função objetivo } \\
\text { linear de tempo juntamente com seis } \\
\text { grupos de restrições foram } \\
\text { formulados. }\end{array}$ \\
\hline
\end{tabular}




\begin{tabular}{|c|c|c|c|c|}
\hline $\begin{array}{l}\text { Empirical research } \\
\text { opportunities in reverse } \\
\text { supply chains }\end{array}$ & Teórico & $\begin{array}{l}\text { Explorar a literatura } \\
\text { sobre cadeia de } \\
\text { suprimento reversa e } \\
\text { sugerir proposições de } \\
\text { pesquisa que poderiam } \\
\text { ser estudadas } \\
\text { empiricamente. }\end{array}$ & $\begin{array}{l}\text { Cadeia de } \\
\text { suprimento } \\
\text { reversa. }\end{array}$ & $\begin{array}{l}\text { Abordar várias oportunidades e } \\
\text { desafios que enfrentam atualmente } \\
\text { os gerentes de negócios que operam } \\
\text { em RSCs. }\end{array}$ \\
\hline $\begin{array}{l}\text { Reverse logistics: } \\
\text { superior performance } \\
\text { through focused } \\
\text { resource commitments } \\
\text { to information } \\
\text { technology }\end{array}$ & Empírico & $\begin{array}{l}\text { Fazer um levantamento } \\
\text { das empresas } \\
\text { automobilísticas sobre } \\
\text { o desempenho da LR e } \\
\text { estratégicas } \\
\text { relacionadas ao } \\
\text { sistema de informação. }\end{array}$ & $\begin{array}{l}\text { LR na indústria } \\
\text { automobilístic } \\
\text { a. }\end{array}$ & $\begin{array}{l}\text { Suporte de informação para } \\
\text { autorizar, controlar e manipular os } \\
\text { retornos pode impactar } \\
\text { positivamente no desempenho com a } \\
\text { qualidade econômica e serviço. }\end{array}$ \\
\hline $\begin{array}{l}\text { Strategic safety stocks } \\
\text { in reverse logistics } \\
\text { supply chains }\end{array}$ & Empirico & $\begin{array}{l}\text { Combinar o problema } \\
\text { de planejamento de } \\
\text { estoque de segurança } \\
\text { com a integração de } \\
\text { devolução do produto } \\
\text { externo e interno e } \\
\text { reutilização. }\end{array}$ & $\begin{array}{l}\text { Rede de } \\
\text { recuperação } \\
\text { do produto. }\end{array}$ & $\begin{array}{l}\text { A integração de retornos de produtos } \\
\text { a sua recuperação para reutilização } \\
\text { como complica a coordenação de } \\
\text { materiais. Com uma extensão do } \\
\text { estoque estratégico de segurança é } \\
\text { possível incorporar esses fluxos. }\end{array}$ \\
\hline $\begin{array}{l}\text { Trust and knowledge } \\
\text { sharing in green supply } \\
\text { chains }\end{array}$ & Empírico & $\begin{array}{l}\text { Analisar como a } \\
\text { confiança interage em } \\
\text { fatores que afetam o } \\
\text { compartilhamento de } \\
\text { conhecimento } \\
\text { interorganizacional no } \\
\text { GSCM }\end{array}$ & $\begin{array}{l}\text { Conhecimento } \\
\text { Interorganaza } \\
\text { cional }\end{array}$ & $\begin{array}{l}\text { Concluiu que a confiança é o pivô dos } \\
\text { fatores que influenciam o } \\
\text { compartilhamento de conhecimento } \\
\text { interorganizacional. }\end{array}$ \\
\hline $\begin{array}{l}\text { Supply planning model } \\
\text { for remanufacturing } \\
\text { system in reverse } \\
\text { logistics environment }\end{array}$ & Empírico & $\begin{array}{l}\text { Discutir o processo de } \\
\text { remanufatura de peças } \\
\text { reutilizáveis em LR. }\end{array}$ & $\begin{array}{l}\text { Rede de } \\
\text { recuperação } \\
\text { de produtos }\end{array}$ & $\begin{array}{l}\text { Maximizar o total de redução de } \\
\text { custos por quantidade de peças a } \\
\text { serem processadas em cada } \\
\text { instalação de remanufatura. }\end{array}$ \\
\hline $\begin{array}{l}\text { An empirical study of } \\
\text { the implementation of } \\
\text { GSCM practices in the } \\
\text { electrical and electronic } \\
\text { industry }\end{array}$ & Empírico & $\begin{array}{l}\text { Investigar as práticas } \\
\text { de GSCM provável de } \\
\text { ser adotada por } \\
\text { a indústria elétrica e } \\
\text { eletrônica em Taiwan. }\end{array}$ & $\begin{array}{l}\text { Avaliação de } \\
\text { Desempenho } \\
\text { Ambiental. }\end{array}$ & $\begin{array}{l}\text { Práticas verdes geraram } \\
\text { performances ambientais e } \\
\text { financeiras favoráveis para as } \\
\text { respectivas empresas. }\end{array}$ \\
\hline $\begin{array}{l}\text { Initiatives and } \\
\text { outcomes of green } \\
\text { supply chain } \\
\text { management } \\
\text { implementation by } \\
\text { Chinese manufacturers }\end{array}$ & Empírico & $\begin{array}{l}\text { Objetivo de explorar o } \\
\text { GSCM e iniciativas de } \\
\text { implementação. }\end{array}$ & $\begin{array}{l}\text { Avaliação de } \\
\text { Desempenho } \\
\text { Ambiental. }\end{array}$ & $\begin{array}{l}\text { Os resultados mostram que a } \\
\text { indústria elétrica e eletrônica alcança } \\
\text { melhores resultados de desempenho } \\
\text { ambiental do que os outros tipos de } \\
\text { fabricantes. }\end{array}$ \\
\hline $\begin{array}{l}\text { Using activity-based } \\
\text { costing to reengineer } \\
\text { the reverse logistics } \\
\text { channel }\end{array}$ & Empírico & $\begin{array}{l}\text { llustrar uma aplicação } \\
\text { real do ABC para } \\
\text { reverter atividades } \\
\text { logísticas realizadas } \\
\text { entre as cadeia de } \\
\text { fornecimento. }\end{array}$ & Custos na LR & $\begin{array}{l}\text { Esta pesquisa demonstrou o } \\
\text { verdadeiro custo das operações de } \\
\text { logística, utilizando o ABC. O esforço } \\
\text { para reduzir o desperdício no canal } \\
\text { inverso beneficiou tanto os varejistas } \\
\text { quanto os distribuidores. }\end{array}$ \\
\hline $\begin{array}{l}\text { A continuous time } \\
\text { inventory model for a } \\
\text { product recovery } \\
\text { system with multiple } \\
\text { options }\end{array}$ & Empírico & $\begin{array}{l}\text { Determinar a produção } \\
\text { ideal, remanufatura e } \\
\text { política de descarte } \\
\text { para um modelo de } \\
\text { custo linear. }\end{array}$ & $\begin{array}{l}\text { Rede de } \\
\text { recuperação } \\
\text { de produto. }\end{array}$ & $\begin{array}{l}\text { Foi apresentada uma dinâmica } \\
\text { contínua para o problema de } \\
\text { recuperação do produto com um } \\
\text { único retorno e múltiplos fluxos de } \\
\text { demanda para diferentes produtos } \\
\text { ou qualidades. }\end{array}$ \\
\hline
\end{tabular}




\begin{tabular}{|c|c|c|c|c|}
\hline $\begin{array}{l}\text { Drivers for the } \\
\text { participation of small } \\
\text { and medium-sized } \\
\text { suppliers in green } \\
\text { supply chain initiatives }\end{array}$ & Empírico & $\begin{array}{l}\text { Descrever o que facilita } \\
\text { os pequenos e médios } \\
\text { fornecedores em } \\
\text { participar de iniciativas } \\
\text { verdes da cadeia de } \\
\text { suprimentos. }\end{array}$ & $\begin{array}{l}\text { Rede de } \\
\text { recuperação } \\
\text { de produto. }\end{array}$ & $\begin{array}{l}\text { O estudo constata o comprador } \\
\text { foram positivamente associados } \\
\text { fornecedores no que se refere à } \\
\text { participação da cadeia de } \\
\text { suprimentos verde. O documento } \\
\text { revela que os fornecedores têm } \\
\text { interesse em participar dessas } \\
\text { iniciativas. }\end{array}$ \\
\hline $\begin{array}{l}\text { The role of resource } \\
\text { commitment and } \\
\text { innovation in reverse } \\
\text { logistics performance }\end{array}$ & Empírico & $\begin{array}{l}\text { Destina-se a fornecer a } \\
\text { evidência empírica das } \\
\text { relações entre a } \\
\text { logística reversa, } \\
\text { comprometimento de } \\
\text { recursos e inovação. }\end{array}$ & $\begin{array}{l}\text { LR na indústria } \\
\text { automotiva. }\end{array}$ & $\begin{array}{l}\text { Os recursos devem ser utilizados de } \\
\text { forma a desenvolver capacidades } \\
\text { inovadoras de manipular os retornos. }\end{array}$ \\
\hline $\begin{array}{l}\text { Managing product } \\
\text { returns for reverse } \\
\text { logistics }\end{array}$ & Empírico & $\begin{array}{l}\text { Apresentar uma } \\
\text { estrutura para gerir } \\
\text { devoluções de } \\
\text { produtos. }\end{array}$ & $\begin{array}{l}\text { Gestão de } \\
\text { retornos na } \\
\text { Índia. }\end{array}$ & $\begin{array}{l}\text { O quadro integrado ajuda a estimar } \\
\text { retornos para determinadas } \\
\text { categorias de produtos e, } \\
\text { posteriormente, tomar decisões } \\
\text { simultâneas em sua disposição, } \\
\text { localização e capacidade das } \\
\text { instalações. }\end{array}$ \\
\hline $\begin{array}{l}\text { A goal programming } \\
\text { model for paper } \\
\text { recycling system }\end{array}$ & Empírico & $\begin{array}{l}\text { Propor a redução de } \\
\text { custo de LR, a melhoria } \\
\text { da qualidade do } \\
\text { produto e os benefícios } \\
\text { ambientais por meio } \\
\text { do aumento da } \\
\text { recuperação de papéis. }\end{array}$ & Custos na LR & $\begin{array}{l}\text { O modelo proposto auxilia na } \\
\text { determinação da localização de } \\
\text { instalações, a via e o fluxo de } \\
\text { diferentes variedades de lixo } \\
\text { reciclável. }\end{array}$ \\
\hline $\begin{array}{l}\text { Development of RFID- } \\
\text { based Reverse Logistics } \\
\text { System }\end{array}$ & Empírico & $\begin{array}{l}\text { Este documento } \\
\text { propõe um algoritmo } \\
\text { para determinar os } \\
\text { locais apropriados para } \\
\text { os pontos de coleta. }\end{array}$ & $\begin{array}{l}\text { Gestão de } \\
\text { retornos. }\end{array}$ & $\begin{array}{l}\text { Os resultados das simulações } \\
\text { indicaram que o algoritmo é capaz de } \\
\text { produzir soluções de boa qualidade } \\
\text { em termos de cobertura de pontos } \\
\text { de recolha, escolhendo locais } \\
\text { adequados para os pontos de coleta. }\end{array}$ \\
\hline $\begin{array}{l}\text { Formalization of } \\
\text { reverse logistics } \\
\text { programs: A strategy } \\
\text { for managing liberalized } \\
\text { returns }\end{array}$ & Empírico & $\begin{array}{l}\text { Analisar as relações } \\
\text { entre a formalização, } \\
\text { políticas liberais e } \\
\text { recursos relacionados e } \\
\text { eficácia global dos } \\
\text { programas de LR. }\end{array}$ & $\begin{array}{l}\text { Gestão de } \\
\text { retornos }\end{array}$ & $\begin{array}{l}\text { Os gestores devem perceber que o } \\
\text { tratamento eficaz das operações de } \\
\text { logística reversa podem resultar em } \\
\text { benefícios econômicos e } \\
\text { estratégicos. }\end{array}$ \\
\hline $\begin{array}{l}\text { Environmental } \\
\text { strategies and green } \\
\text { product development: } \\
\text { an overview on } \\
\text { sustainability-driven } \\
\text { companies }\end{array}$ & Empírico & $\begin{array}{l}\text { Investigar as } \\
\text { abordagens } \\
\text { estratégicas ambientais } \\
\text { adotadas pelas } \\
\text { empresas orientadas } \\
\text { para a sustentabilidade }\end{array}$ & $\begin{array}{l}\text { Estratégias } \\
\text { ambientais } \\
\text { nas empresas. }\end{array}$ & $\begin{array}{l}\text { Diferentes abordagens estratégicas } \\
\text { ambientais são mais elevadas para os } \\
\text { se preocupam com os produtos } \\
\text { verdes e com a sustentabilidade } \\
\text { ambiental. }\end{array}$ \\
\hline $\begin{array}{l}\text { Flexible decision } \\
\text { modeling of reverse } \\
\text { logistics system: A value } \\
\text { adding MCDM } \\
\text { approach for } \\
\text { alternative selection }\end{array}$ & Empírico & $\begin{array}{l}\text { Propor um modelo } \\
\text { para ajudar na } \\
\text { elaboração de política } \\
\text { de devolução de } \\
\text { produtos mais flexível e } \\
\text { eficiente. }\end{array}$ & $\begin{array}{l}\text { Gestão de } \\
\text { retornos. }\end{array}$ & $\begin{array}{l}\text { O método proposto é muito flexível e } \\
\text { fornece informações mais objetivas } \\
\text { para a seleção de alternativas do } \\
\text { sistema de LR., que são complexos e } \\
\text { imprecisos. }\end{array}$ \\
\hline $\begin{array}{l}\text { Environmental- } \\
\text { regulation pricing } \\
\text { strategies for green } \\
\text { supply chain } \\
\text { management }\end{array}$ & Empírico & $\begin{array}{l}\text { Demostrar que um } \\
\text { projeto adequado de } \\
\text { regulamentações e } \\
\text { estratégias para } \\
\text { promover s } \\
\text { Responsabilidade }\end{array}$ & $\begin{array}{l}\text { Rede de } \\
\text { recuperação } \\
\text { de produto. }\end{array}$ & $\begin{array}{l}\text { Descobrimos que os governos } \\
\text { devem optar por aumentar } \\
\text { gradualmente os padrões de } \\
\text { regulamentação para que os } \\
\text { fabricantes possam melhorar } \\
\text { gradualmente a sua capacidade de }\end{array}$ \\
\hline
\end{tabular}




\begin{tabular}{|c|c|c|c|c|}
\hline & & Alargada do Produtor. & & reciclagem do produto. \\
\hline $\begin{array}{l}\text { Green supply chain } \\
\text { management, reverse } \\
\text { logistics and nuclear } \\
\text { power generation }\end{array}$ & Empírico & $\begin{array}{l}\text { Elaborar um modelo } \\
\text { para otimizar as } \\
\text { operações de geração } \\
\text { de energia nuclear e de } \\
\text { LR induzida por } \\
\text { resíduos } \\
\text { correspondentes. }\end{array}$ & $\begin{array}{l}\text { Gestão de } \\
\text { retornos. }\end{array}$ & $\begin{array}{l}\text { Os resultados numéricos indicam que } \\
\text { com o uso da abordagem proposta, o } \\
\text { impacto ambiental induzida incluindo } \\
\text { os custos e riscos correspondentes } \\
\text { podem ser melhorados em até } \\
37,8 \% \text {. }\end{array}$ \\
\hline $\begin{array}{l}\text { Reverse logistics in the } \\
\text { electronic industry of } \\
\text { China: a case study }\end{array}$ & Empírico & $\begin{array}{l}\text { Investigar se os atuais } \\
\text { modelos e teorias de } \\
\text { logística reversa podem } \\
\text { ser totalmente } \\
\text { aplicados em países em } \\
\text { desenvolvimento como } \\
\text { China. }\end{array}$ & $\begin{array}{l}\text { LR na Indústria } \\
\text { eletrônica da } \\
\text { China. }\end{array}$ & $\begin{array}{l}\text { A maior dificuldade na } \\
\text { implementação da LR é a falta de leis } \\
\text { executáveis, regulamentares ou } \\
\text { diretrizes para motivar fabricantes; } \\
\text { políticas para ajudar os fabricantes a } \\
\text { compensar os elevados custos de } \\
\text { investimento de logística reversa. }\end{array}$ \\
\hline $\begin{array}{l}\text { Implementation of } \\
\text { strategic green } \\
\text { orientation in supply } \\
\text { chain. }\end{array}$ & Empírico & $\begin{array}{l}\text { Abordar as questões de } \\
\text { inovação através da } \\
\text { integração e orientação } \\
\text { estratégica, práticas } \\
\text { internas, coordenação } \\
\text { e medidas de } \\
\text { desempenho. }\end{array}$ & $\begin{array}{l}\text { Estratégias } \\
\text { ambientais } \\
\text { nas empresas. }\end{array}$ & $\begin{array}{l}\text { Orientação estratégica verde de uma } \\
\text { empresa envolve práticas verdes, } \\
\text { implementação do programa de } \\
\text { melhoria do ambiente e } \\
\text { compromisso futuro para práticas } \\
\text { ambientais. }\end{array}$ \\
\hline $\begin{array}{l}\text { Drivers of green supply } \\
\text { management } \\
\text { performance: Evidence } \\
\text { from Germany }\end{array}$ & Empírico & $\begin{array}{l}\text { Analisar a eficácia de } \\
\text { diferentes abordagens } \\
\text { utilizadas para } \\
\text { estender as práticas } \\
\text { sustentáveis dos } \\
\text { fornecedores. }\end{array}$ & $\begin{array}{l}\text { Avaliação de } \\
\text { Desempenho } \\
\text { Ambiental. }\end{array}$ & $\begin{array}{l}\text { Os resultados sugerem que o grau de } \\
\text { avaliação de fornecedores verdes e o } \\
\text { nível de colaboração verde exerce } \\
\text { influência direta sobre o } \\
\text { desempenho ambiental. Os } \\
\text { resultados mostram que o } \\
\text { desempenho ambiental tem um } \\
\text { impacto positivo sobre desempenho } \\
\text { da compra. }\end{array}$ \\
\hline $\begin{array}{l}\text { Barriers to the } \\
\text { implementation of } \\
\text { environmentally } \\
\text { oriented reverse } \\
\text { logistics: evidence from } \\
\text { the automotive industry } \\
\text { sector }\end{array}$ & Empírico & $\begin{array}{l}\text { Identificar as barreiras } \\
\text { que impedem ou } \\
\text { dificultam a } \\
\text { implementação de } \\
\text { práticas de LR } \\
\text { ambientalmente } \\
\text { orientadas, com foco } \\
\text { na indústria } \\
\text { automotiva. }\end{array}$ & $\begin{array}{l}\text { LR na indústria } \\
\text { automotiva. }\end{array}$ & $\begin{array}{l}\text { Usando modelagem de equações } \\
\text { estruturais foi possível identificar dois } \\
\text { tipos de barreiras, externas e } \\
\text { internas, e estudar se essas barreiras, } \\
\text { previamente identificados na } \\
\text { literatura, impedem as práticas de LR. }\end{array}$ \\
\hline $\begin{array}{l}\text { An emergy-based } \\
\text { evaluation of a reverse } \\
\text { logistics network for } \\
\text { steel recycling }\end{array}$ & Empírico & $\begin{array}{l}\text { Avaliar um fluxo } \\
\text { reverso } \\
\text { de rede logística para } \\
\text { reciclagem do aço } \\
\text { através da execução } \\
\text { eficiente de redes de } \\
\text { reciclagem. }\end{array}$ & $\begin{array}{l}\text { Redes de } \\
\text { recuperação } \\
\text { de produto. }\end{array}$ & $\begin{array}{l}\text { O uso dos diagramas emergéticos } \\
\text { forneceu uma maneira de avaliar as } \\
\text { estratégias de reciclagem e comparar } \\
\text { os benefícios econômicos e } \\
\text { ambientais relativos. }\end{array}$ \\
\hline $\begin{array}{l}\text { OEM product design in } \\
\text { a price competition } \\
\text { with remanufactured } \\
\text { product }\end{array}$ & Empírico & $\begin{array}{l}\text { Formular um modelo } \\
\text { para investigar a } \\
\text { decisão de projeto do } \\
\text { produto do OEM e } \\
\text { estratégias de preços } \\
\text { competitivos. }\end{array}$ & $\begin{array}{l}\text { Estratégias } \\
\text { ambientais }\end{array}$ & $\begin{array}{l}\text { Ao se concentrar no mercado e } \\
\text { fatores de custo, o modelo capta } \\
\text { vários dos elementos-chaves para as } \\
\text { decisões estratégicas de design de } \\
\text { produto por unidade e preços. }\end{array}$ \\
\hline
\end{tabular}




\begin{tabular}{|c|c|c|c|c|}
\hline $\begin{array}{l}\text { A holistic approach for } \\
\text { decision on selection of } \\
\text { end-of-life products } \\
\text { recovery options }\end{array}$ & Empirico & $\begin{array}{l}\text { O objetivo deste } \\
\text { trabalho é fornecer um } \\
\text { método de decisão } \\
\text { para selecionar a opção } \\
\text { de recuperação de } \\
\text { produto mais } \\
\text { sustentável, }\end{array}$ & $\begin{array}{l}\text { Gestão de } \\
\text { retornos }\end{array}$ & $\begin{array}{l}\text { Esta pesquisa desenvolve e } \\
\text { implementa com sucesso um método } \\
\text { holístico para a tomada de decisão } \\
\text { sobre as opções de recuperação de } \\
\text { produtos apos o ciclo de vida. O } \\
\text { desenvolvimento do método } \\
\text { beneficia da revisão de métodos } \\
\text { anteriores e baseia-se em seus } \\
\text { pontos fortes e evita suas fraquezas. }\end{array}$ \\
\hline $\begin{array}{l}\text { Strategic orientations, } \\
\text { sustainable supply } \\
\text { chain initiatives, and } \\
\text { reverse logistics: } \\
\text { Empirical evidence from } \\
\text { an emerging market }\end{array}$ & Empirico & $\begin{array}{l}\text { Desenvolver e testar } \\
\text { um modelo teórico } \\
\text { para prever como as } \\
\text { iniciativas sustentáveis } \\
\text { da cadeia de } \\
\text { suprimentos podem } \\
\text { influenciar resultados } \\
\text { logísticos reversos. }\end{array}$ & $\begin{array}{l}\text { Gestão de } \\
\text { retornos }\end{array}$ & $\begin{array}{l}\text { Os resultados mostram que as } \\
\text { empresas que implementam } \\
\text { iniciativas da cadeia de suprimentos } \\
\text { sustentáveis podem realizar } \\
\text { resultados positivos de logística } \\
\text { reversa. }\end{array}$ \\
\hline $\begin{array}{l}\text { A review of reverse } \\
\text { logistics and closed- } \\
\text { loop supply chains: a } \\
\text { Journal } \\
\text { of Cleaner Production } \\
\text { focus }\end{array}$ & Teórico & $\begin{array}{l}\text { Rever, categorizar e } \\
\text { avaliar os artigos } \\
\text { relacionados, a fim de } \\
\text { fornecer uma visão } \\
\text { sistemática do trabalho } \\
\text { passado e uma visão } \\
\text { apropriada para o } \\
\text { futuro. }\end{array}$ & $\begin{array}{l}\text { Revisão de } \\
\text { literatura }\end{array}$ & $\begin{array}{l}\text { Os resultados clarificam as principais } \\
\text { tendências em logística reversa e em } \\
\text { assuntos de cadeia de suprimentos } \\
\text { em cadeia fechada para o } \\
\text { Journal of Cleaner Production e as } \\
\text { avaliações revelam algumas } \\
\text { oportunidades sugeridas para novas } \\
\text { direções de pesquisa para o jornal. }\end{array}$ \\
\hline $\begin{array}{l}\text { The closed-loop supply } \\
\text { chain network with } \\
\text { competition and design } \\
\text { for remanufacturability }\end{array}$ & Empirico & $\begin{array}{l}\text { Investigar uma rede de } \\
\text { cadeia de suprimentos } \\
\text { em dois circuitos, com } \\
\text { fabricantes como } \\
\text { decisores } \\
\text { descentralizados que } \\
\text { competem por } \\
\text { compartilhar o } \\
\text { mercado. No }\end{array}$ & $\begin{array}{l}\text { Redes de } \\
\text { recuperação } \\
\text { de produto. }\end{array}$ & $\begin{array}{l}\text { Através de uma série de estudos de } \\
\text { caso, respondemos várias questões } \\
\text { de pesquisa importantes, como o } \\
\text { impacto do design de } \\
\text { remanufaturabilidade e a percepção } \\
\text { dos consumidores sobre o produto } \\
\text { remanufaturado sobre rentabilidade } \\
\text { e participação no mercado. }\end{array}$ \\
\hline
\end{tabular}

Fonte: Elaborado pelos autores.

Quanto a classificação dos artigos selecionados, 19 artigos são do tipo modelagem, 11 são do tipo estudo de caso, 9 do tipo survey e 6 são artigos teóricos, de acordo com a Figura 6. 
Figura 6 - Tipo de artigo do portfólio bibliográfico

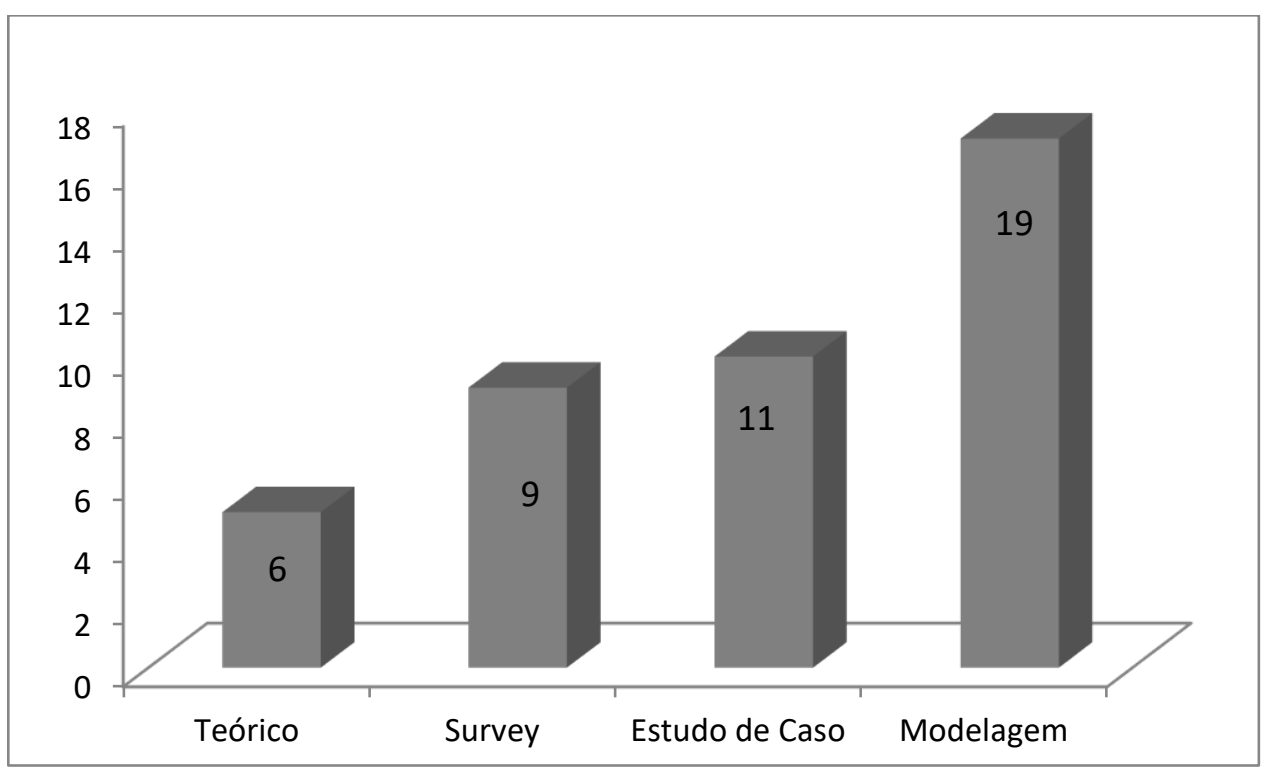

Fonte: Elaborado pelos autores.

Destaca-se o número significativo de artigos do tipo modelagem pelo fato de ferramentas matemáticas serem utilizadas mais frequentemente para descrever os fluxos de retornos, as operações de remanufatura, os processos de recuperação de produtos e os custos ambientais.

No que se refere à unidade de análise ou o foco das pesquisas dos artigos do portfólio bibliográfico, observa-se na Figura 7 que as pesquisas são direcionadas principalmente para a gestão de retornos, rede de recuperação de produtos, seguido de avaliação de desempenho ambiental, custos e estratégias ambientais.

Figura 7 - Unidade de Análise dos Artigos

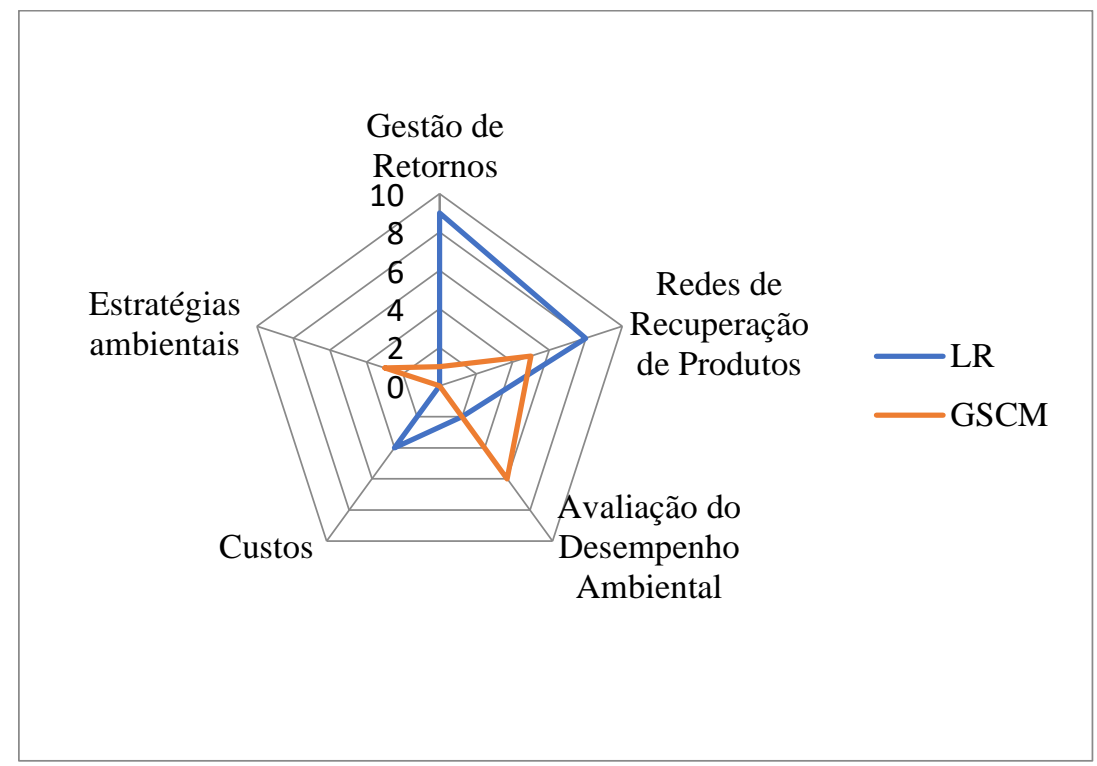

Fonte: Elaborado pelos autores. 
Verifica-se na Figura 6 que as pesquisas voltadas ao tema LR se sobressai ao GSCM, entretanto, os dois temas se complementam. No que diz respeito à unidade de análise Gestão de Retornos, 9 artigos se referem a LR e apenas 1 se concentra no tema GSCM. De acordo com Silva, Renó, Sevegnani and Truzzi (2013), a preocupação das empresas com o retorno dos resíduos fez com que os bens pós-venda e pós- consumo se tornasse parte integrante do processo produtivo. Mendes, Theis, Fagundes, Schereiber e Silva (2016) afirmam que o produto ou resíduo precisa ser inspecionado e classificado para determinar a melhor forma de sua disposição.

No que se refere às Redes de recuperação de Produtos, 8 artigos focam no tema LR e 5 artigos no tema GSCM. Ravi and Shankar (2005) afirmam que os gestores devem demonstrar compromisso da LR com outros objetivos organizacionais, integrando todos os membros de toda cadeia de suprimento. De acordo com os mesmos autores, deve ser fornecido suporte contínuo para a LR nos planos estratégicos e nos planos de ação para o sucesso da implementação em toda a cadeia.

A unidade de análise Avaliação de desempenho ambiental concentra-se principalmente no tema GSCM. O Desempenho Ambiental busca medidas de avaliação ambiental nas indústrias e nas cadeias de suprimentos para melhorar os processos e torná-los mais eficientes (Lee \& Lam, 2012).

As pesquisas com a unidade de análise Custos são predominantemente voltadas ao tema LR. Autores como Kannan (2009) alegam que a LR tem como foco o fluxo de materiais do cliente para o fornecedor com o objetivo de maximizar o valor do item devolvido ou minimizar o custo total. De acordo com Giannetti, Bonilla and Almeida (2012), os custos altos de um sistema eficiente de LR pode se transformar em vantagem competitiva. Já as Estratégias ambientais tem como foco o GSCM.

Ressalta-se um crescente interesse das pesquisas no que se refere à LR em Empresas Terceirizadas, já que as práticas verdes nas indústrias devem incluir todas as empresas que compõe a cadeia de suprimento.

Outro ponto importante do estudo é o conhecimento dos países que lideram as pesquisas dos temas GSCM e LR. Quanto aos países analisados nos artigos, constata-se na Figura 8 que grande parte das pesquisas foram realizadas na China e Taiwan, com 4 artigos respectivamente. 
Figura 8 - Número de artigos por países

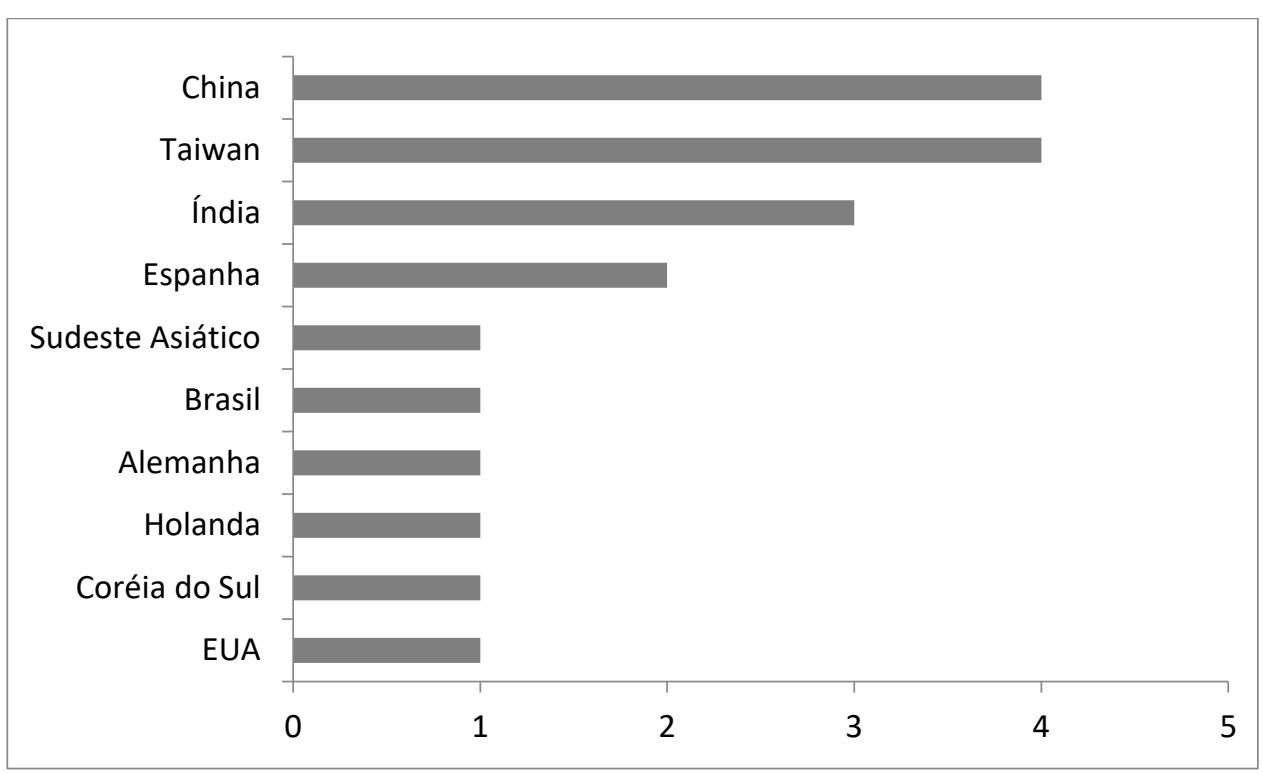

Fonte: Elaborado pelos autores.

As pesquisas são realizadas nesses países, sobretudo pelo seu crescimento econômico emergente, com indústrias de alta tecnologia, serviços e finanças e que, consequentemente, necessitam melhorar o seu desempenho ambiental. Assim, as empresas desses países se veem obrigadas a agir de forma responsável com o meio ambiente seja pelo aumento da concorrência ou para cumprir as exigências ambientais.

Dentro desse parâmetro, foram diagnosticadas as mais relevantes recomendações futuras de 18 artigos sobre os temas GSCM e logística reversa, conforme exposto na Tabela 3.

Tabela 3 - Recomendações Futuras

\begin{tabular}{|l|l|}
\hline \multicolumn{1}{|c|}{ Autor } & \multicolumn{1}{c|}{ Recomendaçães Futuras } \\
\hline $\begin{array}{l}\text { Kroon and Vrijens } \\
\text { (1995) }\end{array}$ & $\begin{array}{l}\text { Compensar o custo inicial elevado de distribuição e de coleta de resíduos } \\
\text { pelas vantagens futuras, como a imagem positiva da empresa. }\end{array}$ \\
\hline $\begin{array}{l}\text { Fleischmann, } \\
\text { DekkerVan der Lann } \\
\text { and Wassenhove } \\
\text { (1997) }\end{array}$ & $\begin{array}{l}\text { Adequar o sistema de informação com as tecnologias modernas para } \\
\text { poder lidar melhor com a incerteza, aperfeiçoar os processos e } \\
\text { aumentar a integração. }\end{array}$ \\
\hline Shih (2001) & $\begin{array}{l}\text { Compartilhar os locais de armazenamento dos produtos retornados } \\
\text { com outras empresas para poder reduzir o custo total. }\end{array}$ \\
\hline $\begin{array}{l}\text { Tibben-Lembke } \\
\text { (2002) }\end{array}$ & $\begin{array}{l}\text { Investigar a LR e a sua conexão com o ciclo de vida do produto para que } \\
\text { a preocupação com o descarte do material esteja inserido na concepção } \\
\text { do produto. }\end{array}$ \\
\hline $\begin{array}{l}\text { Kleber, Minner and } \\
\text { Kiesmüller (2002) }\end{array}$ & $\begin{array}{l}\text { Desenvolver pesquisas que busque contornar a complexidade da rede } \\
\text { de LR, que conta com vários retornos, fontes e destinos. }\end{array}$ \\
\hline $\begin{array}{l}\text { Hervani, Helms, and } \\
\text { Sarkis (2005) }\end{array}$ & $\begin{array}{l}\text { Aumentar a cooperação entre as organizações no que diz respeito à } \\
\text { gestão de produtos, avaliação de desempenho, análise de ciclo de vida } \\
\text { e tecnologias de informações e aprimorar o desempenho dessas } \\
\text { atividades. }\end{array}$ \\
\hline Srivastava (2006) & $\begin{array}{l}\text { Verificar as circunstâncias em que os retornos são manuseados, } \\
\text { armazenados, transportados e processados; comparando o custo de }\end{array}$ \\
\hline
\end{tabular}




\begin{tabular}{|c|c|}
\hline $\begin{array}{l}\text { Prahinski and } \\
\text { Kocabasoglu (2006) }\end{array}$ & $\begin{array}{l}\text { Elaborar técnicas para diminuir a divergência de qualidade dos produtos } \\
\text { devolvidos, como um padrão de qualidade, evitando assim custo } \\
\text { desnecessário. }\end{array}$ \\
\hline Lu and Bostel (2007) & $\begin{array}{l}\text { Melhorar o planejamento e a gestão do processo de remanufatura para } \\
\text { otimizar os sistemas de LR. }\end{array}$ \\
\hline $\begin{array}{l}\text { Chieng and Shih } \\
\text { (2007) }\end{array}$ & $\begin{array}{l}\text { Adotar medidas de prevenção da poluição como principal estratégia de } \\
\text { gestão ambiental. }\end{array}$ \\
\hline $\begin{array}{l}\text { Zhu, Sarkis and Lai } \\
\text { (2007) }\end{array}$ & $\begin{array}{l}\text { Difundir programas de gestão e avaliação do GSCM para poder medir o } \\
\text { desempenho das práticas ambientais. }\end{array}$ \\
\hline $\begin{array}{l}\text { Cheng, Yeh and Tu } \\
\text { (2008) }\end{array}$ & $\begin{array}{l}\text { Construir métodos de avaliação do desempenho ambiental para } \\
\text { descrever o nível de cooperação entre as empresas e as relações de } \\
\text { concorrência. }\end{array}$ \\
\hline $\begin{array}{l}\text { Kim, Song, Kim and } \\
\text { Jeong (2006) }\end{array}$ & $\begin{array}{l}\text { Aplicar o modelo proposto de retornos de peças em outros setores } \\
\text { industriais para verificar se há uma diminuição nos custos. }\end{array}$ \\
\hline Lee (2008) & $\begin{array}{l}\text { Desenvolver iniciativas governamentais que melhore o desempenho } \\
\text { econômico e ambiental dos compradores e fornecedores "verdes". }\end{array}$ \\
\hline $\begin{array}{l}\text { Albino, Balice and } \\
\text { Dangelico (2009) }\end{array}$ & $\begin{array}{l}\text { Abordar as questões de sustentabilidade no que se refere ao } \\
\text { desenvovimento de produtos verdes, produção e LR. }\end{array}$ \\
\hline $\begin{array}{l}\text { Wanhwa, Madaan } \\
\text { and Chan (2009) }\end{array}$ & $\begin{array}{l}\text { Elaborar políticas de devolução de produtos de acordo com critérios } \\
\text { estabelecidos no sistema de LR. }\end{array}$ \\
\hline $\begin{array}{l}\text { Lau and Wang } \\
\text { (2009) }\end{array}$ & $\begin{array}{l}\text { Implementar a LR de acordo com a leis e regulamentos da política de } \\
\text { resíduos. }\end{array}$ \\
\hline $\begin{array}{l}\text { Giannetti, Bonilla } \\
\text { and Almeida (2012) }\end{array}$ & $\begin{array}{l}\text { O governo deve elaborar um método para criar uma estratégia de } \\
\text { recompensa ou incentivo aos praticantes de } L R\end{array}$ \\
\hline
\end{tabular}

As principais questões abordadas para futuras pesquisas referem-se à: melhorar a eficiência dos processos para diminuir os custos, criar estratégias ambientais a fim de melhorar a imagem da organização e a competitividade, elaborar e desenvolver medidas de avaliação de desempenho do GSCM e LR para medir a eficiência dos processos envolvidos, considerar o ciclo de vida do produto e as questões de sustentabilidade com o intuito de englobar as duas questões na produção e no descarte dos produtos, construir políticas eficientes de retornos de materiais, estratégias de recompensa ou incentivo aos praticantes do GSCM e LR para estimular a adesão das práticas ambientais nas empresas.

\section{Conclusão}

Esse trabalho foi elaborado com o intuito de analisar os artigos mais relevantes a respeito dos temas GSCM e logística reversa. Para tanto, foi realizado o processo de coleta de dados, a construção do portfólio bibliográfico e, posteriormente, a análise sistemática dos artigos selecionados.

O método bibliométrico permitiu identificar a relevância acadêmica dos artigos e autores, o número de citações, os principais periódicos e as palavras-chave mais proeminentes do portfólio bibliográfico, composto por 45 artigos alinhados com os dois temas, disponíveis na base de dados wiley, science direct, scopus e web of science. 
A análise sistemática dos artigos identificou as unidades de análises, os principais países do referido estudo, os objetivos dos artigos e os principais resultados. Por meio da referida análise, observou-se que outros temas envolvem GSCM e logística reversa, como questões de sustentabilidade, ciclo de vida do produto, avaliação de desempenho ambiental, competitividade e eficiência empresarial.

As lacunas de pesquisas identificadas foram acerca de: i) compartilhar os locais de armazenamento dos materiais retornados com outras empresas a fim de reduzir o custo ambiental; ii) desenvolver medidas de avaliação de desempenho ambiental para medir a qualidade e a quantidade dos produtos devolvidos com o intuito de evitar custos elevados e mão-de-obra desnecessária; iii) aprofundar as questões de GSCM e logística reversa com a de sustentabilidade, iv) procurar medidas de prevenção da poluição como estratégia de gestão ambiental, considerando o ciclo de vida do produto; v) desenvolver práticas de GSCM e LR como oportunidade de construir uma vantagem competitiva, e não apenas para cumprir exigências legais.

\section{Referências}

Albino, V., Balice, A., \& Dangelico, R. M. (2009) Environmental strategies and green product development: an overview on sustainability-driven companies. Business Strategy and the Environment, $18(2), 83-96$

Autry, C. W. (2005) Formalization of reverse logistics programs: A strategy for managing liberalized returns. Industrial Marketing Management, 34 (7), 749-757.

Bai, C., \& Sarkis, J. (2010) Green supplier development: analytical evaluation using rough set theory. Journal of Cleaner Production, 18(12), 1200-1210.

Beamon, B. M. (1998) Supply chain design and analysis: models and methods. International Journal of Production Economics, 55(3), 281-94.

Carter, C. R., \& Ellram, L. M. (1998) Reverse Logistics: a review of the literature and framework for future investigation. International Journal of Business Logistics, 19(1), 85-103.

Carter, C. R., \& Rogers, D. S. (2007) A framework of sustainable supply chain management:towards new theory". International Journal of Physical: Distribution \& Logistics Management, 38(5), 60-87.

Chen, I. J., \& Sheu, J. B. (2009) Environmental-regulation pricing strategies for green supply chain management. Transportation Research Part E: Logistics and Transportation Review, 45(5), 667-677.

Cheng, J. H., Yeh, C. H., \& Tu, C. W. (2008) Trust and knowledge sharing in green supply chains. Supply Chain Management: An International Journal, 13(4), 283-295.

Cheng, Y. H., \& Lee, F. (2010) Outsourcing reverse logistics of high-tech manufacturing firms by using a systematic decision-making approach: TFT-LCD sector in Taiwan. Industrial Marketing Management, 39(7), 1111-1119.

Chien, M. K., \& Shih, L. H. (2007) An empirical study of the implementation of green supply chain management practices in the electrical and electronic industry and their relation to organizational performances. International Journal of Environmental Science and Technology, 4 (3),383-394. 
Darnall, N., Jason, J. G., \& Handfilel, R. (2008) Environmental Management Systems and Green Supply Chain Management: Complements for Sustainability. Business Strategy and the Environment, 8(1), 3045.

Daugherty, P. J., Richey, R. G., Genchev, S., \& Chen, H. (2005) Reverse logistics: superior performance through focused resource commitments to information technology. Transportation Research Part E: Logistics and Transportation Review, 42 (2), 77-92.

Fleischmann, M., Krikke, H. R., Dekker, R., \& Flapper, S. D. P. (2000) A characterisation of logistics networks for product recovery. Omega, 28 (6), 653-666.

Fleischmann, M., Bloemhof- Ruwaard, J., Dekker, R., Van der Lann, E., \& Wassenhove, L. N. (1997) Quantitative models for reverse logistics: A review. European Journal of Operational Research, 103(1), 1-17.

Fu, X., Zhu, Q., \& Sarkis, J. (2012) Evaluating green supplier development programs at a telecommunications systems provider. Int. J. Production Economics, 140(1), 357-367.

Genchev, S. E. (2009) Reverse logistics program design: A company study. Business Horizons, 52(2), 139-148.

Giannetti, B. F., Bonilla, S. H., \& Almeida, C. M. V. B. (2012) An emergy-based evaluation of a reverse logistics network for steel recycling. Journal of Cleaner Production, 46, 48-57.

Goldsby, T. J., \& Closs, D. (2000) Using activity-based costing to reengineer the reverse logistics channel. International Journal of Physical Distribution \& Logistics Management, 30 (6), 500-514.

González-Torre, P., Alvarez, M., Sarkis, J., \& Adenso-Díaz, B. (2010) Barriers to the implementation of environmentally oriented reverse logistics: evidence from the automotive industry sector. British Journal of Management, 21, 889-904.

Gonvidan, K., \& Soleimani, H. (2017) A review of reverse logistics and closed-loop supply chains: a Journal of Cleaner Production focus. Journal of Cleaner Production, 142, 371-384.

Handfield, R., Sroufe, R., \& Walton, S. (2005) Integrating Environmental Management and Supply Chain Strategies, Business Strategy and the Environment, 14, 1-19.

Hervani, A., Helms, M., \& Sarkis, J. (2005) Performance measurement for green supply chain management. Benchmarking: An International Journal, 12 (4), 330-353.

Hsu, C-C., Tan, K-H., \& Zalaini, Z.H.M. (2016) Strategic orientations, sustainable supply chain initiatives, and reverse logistics: Empirical evidence from an emerging Market. International Journal of Operations \& Production Management, 36 (1), 86-110.

Hong, P., Know, H. B., \& Roh, J. J. (2009) Implementation of strategic green orientation in supply chain: An empirical study of manufacturing firms. European Journal of Innovation Management 12 (4) 512 532.

Hu, T-L, Sheu, J-B., \& Huang, K-H. (2002) A reverse logistics cost minimization model for the treatment of hazardous wastes. Transportation Research Part E: Logistics and Transportation Review, 38(6), 457473.

Kannan, G. (2009). Fuzzy approach for the selection of third party reverse logistics provider. Asia Pacific Journal of Marketing and Logistics, 21(3) 397-416. 
Kim, K., Song, I., Kim, J., \& Jeong, B. (2006) Supply planning model for remanufacturing system in reverse logistics environment. Computers \& Industrial Engineering, 51(2), 279-287.

Kleber, R., Minner, S., \& Kiesmüller, G. (2002) A continuous time inventory model for a product recovery system with multiple options. International Journal of Production Economics, 79 (2), 141-151.

Knemeyer, A. M., Ponzurick, T. G., \& Logar, C. M. (2002) A qualitative examination of factors affecting reverse logistics systems for end-of-life computers. International Journal of Physical Distribution \& Logistics Management, 32 (6), 455-479.

Kroon, L., \& Vrijens, G. (1995) Returnable containers: an example of reverse logistics, International Journal of Physical Distribution \& Logistics Management, 25 (2), 56-68.

Krumwiede, D. W., \& Sheu, C. (2002) A model for reverse logistics entry by third-party providers. Omega, 30 (5), 325-333.

Lamming, R., \& Hampson, J. (1996) The environment as a supply chain issue. British Journal of Management, 7 (1), 45-62.

Large, R. O., \& Thomsen, C. G. (2011) Drivers of green supply management performance: Evidence from Germany. Journal of Purchasing and Supply Management, 17 (3),176-184.

Lau, K. H, \& Wang, Y. (2009) Reverse logistics in the electronic industry of China: a case study. Supply Chain Management: An International Journal, 14 (6), 447-465.

Lee, C. K. M., \& Chan, T. M. (2009) Reverse Logistics System. Expert Systems with Applications, 36(5), 9299-9307.

Lee, C. K. M., \& Lam, J. S. L. (2012) Managing reverse logistics to enhance sustainability of industrial marketing. Industrial Marketing Management, 41 (4), 589-598.

Lee, S-Y. (2008) Drivers for the participation of small and medium-sized suppliers in green supply chain initiatives. Supply Chain Management: An International Journal, 13 (3)185 -198.

Leonidou, L. C. (2004) An Analysis of the Barriers Hindering Small Business Export Development. Journal of Small Business Management, 42 (3), 279-302.

Lu, Z., \& Bostel, N. (2007) A facility location model for logistics systems including reverse flows: The case of remanufacturing activities. Computers e Operations Research, 34 (2), 299-323.

Meade, L., \& Sarkis, J. (2002) A conceptual model for selecting and evaluating third-party reverse logistics providers. Supply Chain Management: An International Journal, 7 (5), 283- 295.

Mendes, G. S., Theis, V., Fagundes, C., Schereiber, D., \& Silva, M. O. (2016) Logística reversa: estudo de caso em uma indústria de artefatos plásticos. Exacta, 14 (1), 37-45.

Meyer, H. (1999) Many happy returns. Journal of Business Strategy, 20 (4)27-31.

Minner, S. (2001) Strategic safety stocks in reverse logistics supply chains. International Journal of Production Economics, 71 (3), 417-428.

Pati, R. K., Vrat, P., \& Kumar, P. (2008) A goal programming model for paper recycling system. Omega, 36 (3), 405-417. 
Prahinski, C., \& Kocabasoglu, C. (2006) Empirical research opportunities in reverse supply chains. Omega, 34 (6), 519-532.

Qiang, Q. P. (2015) The closed-loop supply chain network with competition and design for remanufacturability, Journal of. Cleanear Production., 105,348-356.

Rao, P., \& Holt, D. (2005) Do green supply chains lead to competitiveness and economic performance? International Journal of Operations \& Production Management, 25 (9), 898 -916.

Ravi, V., \& Shanker,V. (2005) Analysis of interactions among the barriers of reverse logistics. Technological Forecasting \& Social Change, 72 (8), 1011-1029.

Richey, R. G., Genchev, S., \& Daugherty, P. J. (2005) The role of resource commitment and innovation in reverse logistics performance. International Journal of Physical Distribution \& Logistics Management, 35 (4), $233-257$.

Rogers, D. S., Lambert, D. M., Croxton, K. L., \& García-Dastugue, S. J. (2001) The returns Management Process. Journal of Logistics Management, 13 ( 22), 43-57.

Rogers, D. S., \& Tlbben-lembke, R. (2001) An Examination of reverse logistics pratices. Journal of Business Logistics, 22 (2), 129-148.

Salema, M. I. G., Povoa, A. P. B., \& Novais, A. Q. (2007) An optimization model for the design of a capacitated multi-product reverse logistics network with uncertainty. European Journal of Operations Reserach, 179(3), 1063-1077.

Sarkis J., \& Zhu Q.(2008) An Inter-Sectoral Comparison of Green Supply Chain Management in China: Drivers and Practices. Journal of Cleaner Production, 14(5), 472-486.

Sarkis, J. (2003) A strategic decision framework for green supply chain management. Journal of Cleaner Production, 11(4), 397- 409.

Sheu, J- B., Chou, Y. H., \& Hu, C. C. (2005) An integrated logistics operational model for green-supply chain management. Transportation Research Part E: Logistics and Transportation Review, 4(4), 287313.

Sheu, J.-B. (2008) Green supply chain management, reverse logistics and nuclear power generation. Transportation Research Part E: Logistics and Transportation Review, 44(1), 19-46.

Shih, V.G., Lenny; S. C., Baldwin, J., \& Cucchiella, F. (2012) Natural resource based Green supply chain management. Supply Chain Management: An International Journal, 17(1),54-67.

Shih, L. H. (2001) Reverse logistics system planning for recycling electrical appliances and computers in Taiwan. Resource Conservation and Recycling, 32(1), 55-72.

Shukla, A. P., Deshmukhd, S.G., \& Kanda. (2009) Environmentally responsive supply chains Learnings from the Indian auto sector. Journal of Advances in management Research, 6 (2), 1-18.

Silva, D. A. L., Renó, G. W. S., Sevegnani, G., Sevegnani, T. B., \& Truzzl, O. M. S. (2013) Comparison of disposable and returnable packaging: a case study of reverse logistics in Brazil. Journal of Cleaner Production, 47, 377-387.

Srivastava, S. K. (2007) Green supply-chain managemyanent: A state-of the-art literature review. International Journal of Management Reviews, 9(1), 53-80. 
Srivastava, S. K. (2008) Network design for reverse logistics. Omega, 36(4), 325-333.

Srivastava, S. K., \& Srivastava, R. K. (2006) Managing product returns for reverse logistics. International Journal of Physical Distribution \& Logistics Management, 36(7), 524-546.

Tibben-Lembke, R. S. (2002) Life after death: reverse logistics and the product life cycle. International Journal of Physical Distribution \& Logistics Management, 32(3), 223-244.

Tibben-Lembke, R. S. (1998) The impact of reverse logistics on the total cost ofownership. Journal of Marketing Theory and Practice, 6(4), 51-60.

Tibben-Lembke, R. S., \& Rogers, D. S. (2002) Differences between forward and reverse logistics in a retail environment. Supply Chain Management: An International Journal, 7(5), 271-282.

Wanhwa, S., Madaan, J., \& Chan, F.T.S. (2009) Flexible decision modeling of reverse logistics system: A value adding MCDM approach for alternative selection. Robotics and Computer-Integrated Manufacturing, 25(2)460-469.

Wu, C.H. (2013) OEM product design in a price competition with remanufactured product. Omega, 41(2), 287-298.

WU, H. J., \& Dunn, S. (1995) Environmentally responsible logistics systems", International Journal of Physical Distribution \& Logistics Management, 25 (2), 20-38.

Zhang, H. C., Kuo, T. C., \& LU, J. (2005) Environmentally conscious design and manufacturing: a stateof-theart survey. Journal of Manufacturing Systems, 16(5),352-371.

Zhu Q., \& Sarkis J. (2008) An Inter-Sectoral Comparison of Green Supply Chain Management in China: Drivers and Practices. Journal of Cleaner Production, 14(5). 472-486.

Zhu Q., Sarkis J., \& Geng, Y. (2005) Green supply chain management in China: pressures, practices and performance. International Journal of Operations \& Production Management, 25(5) 449-468.

Zhu, Q., Sarkis, J., \& Lai, K.H. (2007) Initiatives and outcomes of green supply chain management implementation by Chinese manufacturers. Journal of Environmental Management, 85 (1), 179-189.

Ziout, A., Azab, M., \& Atwan. (2014). A holistic approach for decision on selection of end-of-life products recovery options. Journal of Cleaner Production, 65, 497-516.

Recebido em: 09 mar. 2018 / Aprovado em: 14 set. 2018

Para referenciar este texto

American Psychological Association (APA)

Silva, F. L. da, Vaz, C. R., \& Lezana, A. G. R. (2020, out./dez.). Green supply chain management e logística reversa: uma análise sistemática dos artigos. Exacta, 18(4), 686-707. https://doi.org/10.5585/exactaep.v18n4.8457. 